\title{
Using standards to improve performance
}

\author{
Peter J. Dean
}

The Pennsylvania State University

\begin{abstract}
The purpose of this article is to explore the nature and applications of professional standards for those in the training field. It provides background information regarding the growth of the profession and the creation of professional standards by the International Board of Standards for Training, Performance and Instruction. Detailed attention is given to the use of competencies in clarifying roles within the profession, hiring, establishing job expectations, planning professional growth opportunities, evaluating performance, succession planning, and knowing when training is not the solution to a performance problem. The growing issue of certification is also discussed. Emphasized throughout the article is how competencies enable us to communicate more clearly the roles and functions of the training profession, thereby enhancing professional credibility.
\end{abstract}

\section{Training to improve performance has always existed}

As long as there have been skills, there has been training to prepare the new generation to take over for the old. Initially it was "one on one, onthe-job training" - whether the job was hunting the family dinner or the employer-employee apprenticeship that exchanged skills and knowledge for free labour. With the increase in technology and the need to constantly retrain workers, assigning new workers to the seasoned veterans was no longer effective. The veterans needed training of their own. Over time employers assigned in-house people to instruct others, a practice that accelerated at the same speed with which technological innovations and improvements appeared on the market. 


\section{Training as a profession}

Eventually a wide variety of learning programs were set up, ranging from informal classes offered by unions to assure a minimum competency level among their members, to the land grant colleges designed to help farmers improve their production. Only since 1940, however, has training, apart from academia, become a profession of its own. It was at this point that written material began to appear about training and human resource development.

Given the rate of change in technology and the marketplace, the advancements in theories of learning, instructional design and organizational development, the recency of programs to prepare practitioners, and the increased emphasis on performance improvement as opposed to retraining; the growth of this profession has been a dynamic one. This has had many benefits, there has been the ability to integrate change and eliminate what doesn't work. On the less positive side, however, there have been a proliferation of job titles and an overlap in functions which have hampered communication among the members of the profession, as well as with management (Nadler, 1984). This lack of consensus as to what roles and functions define the field, as well as the growing number of personnel assigned performance improvement functions without any preparation as trainers, has been a cause of concern for many in the profession, especially as training has expanded beyond the trades into the corporate arena.

\section{Professions have standards}

Traditionally, professions are characterized by sets of roles, common language and functions, the need for specialized preparation, organizations of members, and, ultimately, by their products. As a profession matures, it also includes a means of self-monitoring - of assuring that its practitioners uphold professional standards and perform at a minimum level of competency. These standards evolve from the membership for the purpose of maintaining and increasing the credibility and accountability of those in the profession - and thereby guaranteeing continued employment.

\section{Developing standards for training professionals}

In 1978, two of the professional groups involved in training for performance improvement, the National Society for Performance and Instruction and the Association for Educational Communications and Technology, formed a Joint Task Force of over thirty practitioners and academics with expertise in training, performance and instruction for the purpose of establishing professional standards. This group, The International Board of Standards for Training, Performance and 
Instruction, (IBSTPI) has developed detailed lists of competencies for the positions of instructor, instructional designer and training manager (Professional Reference Guide to the Competencies, 1989). The purpose of the competencies is to say

If you are an instructional designer, an instructor or a manager of training; these are, at least, some of the competencies you should be practicing. . .

and if you are practicing them we should be seeing some real performance improvement both among training professionals and among the audiences they serve!

There is a separate manual devoted to each set of competencies. It is significant to note that the title of each of these manuals includes the word "standards," Instructor Competencies: the Standards, for instance, thus distinguishing "standards" from "competencies." According to Webster's New World Dictionary, a standard is "a level or grade of excellence, attainment." Competency, on the other hand, is having "ability, skill, or fitness." Certainly competence is determined according to some criteria, but is does not necessarily denote accomplishment above the norm. The word standard, however, does denote accomplishment above the norm. What IBSTPI was encouraging through its efforts is the development of professional standards - performance goals - that are represented by a specified set of basic competencies - skills. That is, taken together, the set of competencies identified for a training manager become the performance standards for that role. Throughout this article, the word standards will refer to the performance expectations that are established by the collection of competencies. Competencies will be taken to mean the skills required by training professional.

Before we examine the ways these standards can be used to improve performance, however, it is important to understand how standards are arrived at in the first place.

\section{Deriving valid competencies}

The competencies that were identified by the Task Force "are the product of many years of research and experimentation" (Instructional Designer Competencies: The Standards, p.1, 1986). The professionals working on the Task Force were divided into three groups, each of which focused its attention on one of the roles within the training field: instructor, instructional designer or training manager. Although each group functioned independently, in all cases "the competencies are the result of research into the available literature, internal corporate documents, observations, peer reviews, and evaluation" (Instructor Competencies: The Standards, p.1, 1988). The accomplishments of these groups are represented in four volumes:

- Instructor Competencies: The Standards 
- Instructional Design Competencies: The Standards

- Training Manager Competencies: The Standards

- The Professional Reference Guide to the Competencies: Standards for Instructors, Instructional Designers and Training Managers

The competencies that evolved from this effort were not simply a list of skills.

Each competency is broken down into component performances. Each performance has corresponding conditions under which it is done and criteria of performance. For most competencies, there are three performance levels:

- Doing: Writing a product or conducting of a process.

- Judging: Assessing the adequacy of a product or process done by (your self or) another development team member.

- Giving rationale: Stating the theoretical framework or model which governs the performance.

In many cases (for instructional designers and instructors), the products of performances in one competency are inputs to the next. Thus, while the sequence of the competencies is not meant to define a particular procedure, the performances described do build upon one another. (Instructional Design Competencies: The Standards, 1986, p.1-2)

All competencies include a minimum of three performances, each of which is "unpacked," as illustrated below in the first performance of each sample competency.

\section{Exhibit 1: Instructional Design Competencies: THE STANDARDS}

COMPETENCY ONE: Determine projects that are appropriate for instructional design.

Performance One: Discriminate between situations requiring instructional design solutions from those requiring other solutions (e.g., job redesign, organizational development) and decide if a project is appropriate for instructional design.

Conditions: Given a problem symptom, a problem statement or a proposed problem solution with several different sub-problems and a comprehensive description of an organization,

Behaviour: identify the situations that would best be solved through instructional design and those that would best be solved with other solutions,

Criteria: so that the sub-problems selected as appropriate for instructional design:

a. involve a knowledge, skill or attitude defect;

b. conform to organizational expectations regarding problem solutions; and

c. are not solvable by more effective/efficient non-instructional design solutions. 
Performance Two: Judge the appropriateness and accuracy of instructional design selection decisions...

Performance Three: State a rationale for the decision....

COMPETENCY TWO: Conduct a needs assessment.

Performance One: Develop a needs assessment plan.

Conditions: Given a problem symptom, a problem statement or a proposed problem solution with several different sub-problems and a comprehensive description of an organization

Behaviour: develop a needs assessment/ analysis plan,

Criteria: that:

a. includes at least:

- objective(s) of the needs assessment / analysis,

- identification of the target audience,

- procedures for sampling the target audience and organizational objectives according to accepted professional practice,

- strategy and tactics for data collection according to acceptable professional practice,

- specifications of instruments or protocols to be used according to accepted professional practice, and

- methods of data analysis to yield results congruent with data according to acceptable professional practice,

- description of how decisions will be made based on the data;

b. is feasible to implement and takes into consideration at least:

- organizational resources and constraints, e.g., personnel, finances, time, and

- requirements of information needed to diagnose the presented problem.

Performance Two: Conduct a needs assessment / analysis...

Performance Three: Identify instructional problems...

Performance Four: Judge the appropriateness, comprehensiveness and accuracy of given needs assessment / analysis plans and identified instructional problems..

Performance Five: State a rationale for the plan, interpretation or judgement...

(Instructional Design Competencies: The Standards, 1986, p. 23 -27) 
The detail with which each competency is addressed represents a careful analysis of the roles and functions of training professionals; not for the purpose of prescribing the thoughts and actions, but for the purpose of encouraging responsible, well designed job performance. In other words, competencies of this kind establish criteria that can serve as standards within the profession. But their value is even greater than that. In the paragraphs that follow, we will look at how professional standards:

- improve accountability by clarifying expectations and increasing attention to the key accomplishments of the positions which improve the likelihood of great versus good training;

- are applied to the training and management of training professionals;

- answer some nagging questions such as when is training not an appropriate intervention and how can we avoid the tendency of evolving professions to become exclusionary.

\section{ACCOUNTABILITY - becoming the best we can be}

\section{Professional standards - a requisite}

An emphasis on competencies isn't meant to imply that those of us in the training field have been incompetent. Hardly, the credibility and acceptability that the profession has earned is the result of a lot of fine training. This emphasis is simply a necessary process in the evolution of a profession. It is to the advantage of training professionals to promote professional standards.

Research has clearly shown that good training can result in cost savings and profit for an organization. Until training evaluation becomes more of a science, however, trainers will continue to be extended a greater measure of "good faith" than perhaps anyone else in an organization. That is, managers empower them to do what they do trusting that training objectives will be met and that they will have the long term impact they were intended to, not because every training program results in documented savings to the organization.

This trust will be extended only as long as training professionals function as responsibly as possible to produce the results. Standards help to define responsible performance - and guarantee that performance and productivity objectives will be met.

\section{Clarifying who does what by when}

If you were to look at three different organizations engaged in training, you would, most likely, have three different approaches to training. One organization might have a training department with a full complement of professionals: instructional designers, instructors and a training manager who reports directly to a Vice-President of Human Services. In the second 
organization, training may be the responsibility of an HRD director who may has three trainers to carry out the staff development for the company, while the director divides his/her attention among the various HRD functions. The third organization, equally committed to training, believes in a decentralized approach and has one trainer in each of its organizational units who must work with the unit manager to design, develop and deliver training.

None of these approaches is necessarily better than the other. Commitment from top management and a supportive corporate culture are more important than any one organizational pattern. Another key ingredient is a clear understanding of the training functions. When there are multiple roles in organization which are all devoted to one end result, as with a training department; there is the potential for confusion as to who does what when or potential for an overlap in functions. On the other hand, when training is the responsibility of individuals who have not been prepared as instructional designers or trainers, there is a need for vision as to what training can accomplish and what functions are necessary to achieve the accomplishments. The standards and competencies developed by IBSTPI can address each of these situations.

With the aid of these competencies, both veterans and persons new to the training field can feel more confident in determining who does what by when to produce required training. In some cases, this may simply involve clarifying roles; in other cases, it may mean that certain competencies accorded an instructional designer are assumed by a trainer, while other competencies are taken over by the manager in charge. The point is that, with knowledge of all the important functions and their relative sequence, a plan can be developed that assures the functions are carried out by someone on the "training team."

The skills that together constitute core competencies must coalesce around individuals whose efforts are not so narrowly focused that they cannot recognize the opportunities for blending their functional expertise with those of others in new and interesting ways (Prahalad \& Hamel, 1990, p.82).

\section{Validating the functions of a position}

When those persons responsible for training are not familiar with all of the training functions, there may be a tendency to omit some functions for the sake of time or money, or simply because the manager doesn't see their value. For instance, a training manager may not want her trainers to spend time polishing up their questioning skills. "Anyone can ask questions!!", she says. The fact that one of the competencies of a good trainer is excellent questioning skills (Competency \# 7: Demonstrate effective questioning skills and techniques.) validates to the manager the need to train-thetrainer in the area of questioning skills. At the very least, it opens the door for a dialogue regarding the impact that good questioning techniques have 
on performance improvement and the consequent value of studying and practicing these techniques in order to increase the likelihood that trainees will meet performance objectives.

\section{Providing a foundation for identifying exemplary training professionals}

Those organizations which invest in training do so in order to achieve and maintain a competitive edge within their market. Implicit in achieving this goal is the need for employee training that will address the skills, information and attitudes that distinguish exemplary employee performance from average performance. This kind of professional support and development can only be provided by personnel who are themselves exemplary performers.

Exemplary performance is the most sustained worthy performance that we can reasonably expect to attain. (Gilbert, 1978, p.40)

The sets of competencies developed by IBSTPI do not claim to represent the performances that distinguish exemplary from average training professionals. Taken together as professional standards, however, they enable a training professional to focus more on accomplishments and less on personal style or verbal acumen as indicators of competence. As a result, the evaluation of their performance can be properly focused on accomplishments.

Worthy performance plots valuable accomplishment against costly

behaviour. It says we are far too prone to judge people by their style and

their behaviour than by the effects that they have on the world. (Gilbert,

p.19, 1979)

Educational research has shown that in order to encourage maximum performance in both trainees and employees, you must set high expectations (Rosenthal \& Jacobson, 1968). It would follow that to improve job performance, descriptions indicating the critical attributes or behaviours that are common to the most effective performance levels would be desirable as a model for others in the same position. As part of the growth and development of a profession, it is necessary to determine its basic competencies and standards before establishing those key accomplishments that distinguish exemplary professionals from average ones. The competencies provide a baseline from which to work in establishing the accomplishments that are unique to exemplary instructional designers, instructors or training managers.

\section{Emphasizing systematic thinking on the part of training professionals}

Recent years have seen changes in the way training is viewed by leaders of business and industry. Whereas it was once considered a luxury, it is now 
looked on as one of THE factors that contributes to gaining and maintaining a competitive position in the market place. Even with the trend in downsizing, there are still training positions to be had. As a result, there is an increasing number of individuals who are entering the profession, some through in-house transfer, some as a result of career change. This influx brings with it new and creative energy that will enhance the profession. It also brings some who are not prepared for the rigour the roles demand and think that with a ready tongue and a quick wit, anyone can be a trainer. These individuals are well aware of some of the tasks required of a training professional. They may not, however, have a vision for the systematic process involved in designing and delivering the kind of training that solves performance and productivity problems within an organization. Nor are they likely to be cognizant of those situations for which training is not the appropriate solution.

Performance standards are essential in holding such persons accountable and assuring that the needs of the organization or client are being served. The sequence of the competencies looks to an end result - the solution of the problem - an increase in productivity or improvement in performance. This emphasis demands that training professionals think systematically and not isolate their attention to the functions they perform well or like.

\section{APPLICATION - translating competencies into tools and processes}

Standards serve a profession only if they are used appropriately.

Core competence does not diminish with use. Unlike physical assets, which do deteriorate over time, competencies are enhanced as they are applied and shared. But competencies still need to be nurtured and protected, knowledge fades if it is not used (Prahalad \& Hamel, p 82, 1990).

The International Board of Standards for Training, Performance and Instruction suggests that the competencies, behaviours and criteria they developed can be used to help a training department:

- evaluate the quality of training courses it develops,

- evaluate the quality of training delivery,

- evaluate the effectiveness of the department and its products,

- identify the professional development needs of the current staff,

- develop a job description,

- evaluate prospective candidates for positions in the department,

- develop and/or select courses or curicula to train the professionals in the department,

- develop a systematic approach to developing and implementing and managing training. (Professional Reference Guide to the Competencies, pp. $25,137,288,1989)$ 
Although each competency is thoroughly explained, none are designed to be used by simply retyping them under the headings "Job Description" or "Performance Appraisal Criteria," etc. Rather, they provide the data necessary for an organization to develop its own performance based professional development management system and all of the tools and processes that go along with that.

Such a system for planning and managing the professional growth of instructional designers, instructors or training managers would:

- have imbedded in it all of the factors necessary for professional development

- assure consistency in both management and development of these professionals by using a common set of standards as the building blocks for policies and procedures

- increase the congruity of training programs across organizations.

It is necessary for any organization to adapt the specific competencies to their own culture and goals. The following outlines some strategies that might be used in translating competencies into tools and processes to improve performance within the training profession.

\section{Hiring}

Competencies can be used as a baseline against which to evaluate the training and experience of applicants for training positions. This evaluation can be facilitated in several ways.

If past behaviour is the best predictor of future behaviour, perhaps employers would hire more fully competent people if instead of trying to infer confidence and commitment from a projected image in the job interview, they required tangible evidence of success and competencies. (Hultman, 1988, pp. 36-37)

This evidence can be gathered in several ways.

- Applicants can be given a pre-interview assignment which might including reading the competencies (performances, assumptions, conditions, behaviour, criteria) in preparation for interview questions or for writing an essay related to one or more of the competencies. For instance, "What difficulties might you anticipate in adapting these competencies within an organization and how would you overcome them?" An applicant's critical thinking and problem solving skills, ability to write with clarity and develop ideas in a logical manner, as well as his/ her understanding of the competencies could be evaluated in a preinterview writing assignment. 
- Interview questions can be structured to gather information regarding an applicant's knowledge and experience related to various competencies. For instance, "What past accomplishments illustrate your skill in using instructional methods appropriately?" ( Instructor \#10) or "Explain the steps you've used in conducting a needs assessment."

(Instructional Designer \#2)

Perhaps best of all, the specific performances, behaviours and criteria that accompany each of IBSTPI's competencies provide a baseline for evaluating responses.

\section{Job expectations}

To clarify what is expected on the job is essential if that the job is to be well done. This is not achieved by simply listing those skills or tasks necessary for the completion of a job, it requires an understanding of what the tasks are designed to accomplish so that the competencies are not ends in themselves but become means to an end. This implies that the roles of instructional designer, trainer or training manager are dynamic ones and that the persons fulfilling these roles may need to emphasize one competency over another on a particular project. This flexibility can be achieved if a designer is able to apply the competencies and can subsume one in another or appropriately judge when one should be omitted.

This flexibility can only be achieved if all those involved in making decisions about training have the same expectations for a particular role. A customized set of job expectations can be created by breaking down the competencies into their performances and behaviours and identifying / prioritizing those that are most consistent with the needs and culture of the organization.

During this process a common understanding can be arrived at regarding the policies and procedures, available resources, lines of communication, timelines, etc that characterize the organization. The process also serves as a forum for identifying the end accomplishments that should be the result of the competencies and the criteria by which the professional's performance and accomplishments will be measured.

The result of this process can be viewed as a "contract" among those involved. In essence, the agreement of each participant indicates his/her understanding of and commitment to the terms of the "contract" whether they be in the form of a job description, set of policies and procedures, a performance appraisal or a professional growth plan.

\section{Training / professional growth}

Once there is agreement as to the requirements of a particular position, it is necessary to identify the skills or knowledge needed by the person who has to meet these requirements. This "needs assessment" which identifies 
any gaps between the current knowledge and skills level of a job holder and the ideal is no less important for training professionals than it is for the people they train. The performances associated with each of the competencies provides the information that can be used in conducting such an assessment.

\section{Evaluation}

A good evaluation is objective-based; that is, it measures the extent to which training, management or program objectives have been met. (Mayer, 1984) The specific objectives provided by a competency-based, professional development management system provide the criteria against which to measure accomplishments - a means of identifying which behaviours have met or exceeded the criteria, and which have not.

Commitment and confidence may be inferred from behaviour, but competence must be observed directly Incompetent employees cannot pretend to know what they're doing for long. When assessing actual ability, the bottom line is simple: You can do a task, you can be trained to do it, or you cannot or will not do it. (Hultman, p. 36, 1988)

One approach to using competencies to assess whether participants remember what they were supposed to have learned - and know how to apply it was suggested by Erickson (1990). It involved distilling training goals into competencies that are addressed in training. Three to six months later the trainees were asked to describe how they would handle jobrelated situations.

The evaluator referred frequently to a check sheet that listed the competencies being tested in each case study, and checked them off as they were demonstrated. (The cased studies were designed) so that each competency could be used at least three times. If the participant correctly used a competency at least twice during the interview, the expert credited him or her with a working knowledge of that competency. (pp.57-58)

Competency based accomplishments can also be documented by means of:

- Performance checklists

- Content and construct validity of products such as training modules and support materials. (Smith \& Merchant, 1990)

- Observation by peers and supervisors

- Degree to which an organization's employees meet performance based objectives as a result of participation in courses offered by the training department.

\section{Succession planning}

In the past, the number of years in an organization or a favourable relationship with a supervisor might have influenced raise and promotion 
practices. Specific competencies make it possible to base salary increase and promotion on performance. For instance, if a professional growth management system is in place, succession planning is made much easier. Let's see how this might work with the position of instructor.

If the instructor competencies are used to evaluate the experience, training and potential of candidates; a supervisor can be more confident that there is a good match between the position and person selected. If it is likely that an entry level instructor may advance to master instructor or director of training, the degree to which a candidate displays some of the competencies for these positions can be taken into consideration.

If performance appraisal goals are cooperatively developed, the kind of personal and/or professional growth goals which an instructor undertakes can be an indicator of his/her initiative and potential.

Once job expectations and performance measures have been established; professional growth / management strategies can be identified. Some of these strategies may be designed to prepare the instructor for additional responsibility.

Carefully defined job expectations make it possible to identify when employees are and are not fulfilling job requirements. Those that are can be eligible for a standard automatic raise. Those that aren't can be given ongoing coaching and feedback.

If, after coaching, feedback and training, an employee still does not meet competency levels; he/she can be transferred to a more appropriate job or, if necessary, fired. (Deeprose, 1989)

The documentation that is part of the management system can provide information regarding the effectiveness of an instructor, motivation, willingness to learn, or mastery of new skills, as well as how quickly personal, position and professional growth goals have been reached.

Competencies not only make the supervisor's job easier by providing guidelines and increasing objectivity, they make it easier on the employee as well. If an instructor knows that he or she must reach a specified level of attainment to secure a salary increase or an opportunity for promotion, he can focus his efforts in that direction.

\section{Certification}

...certification has been a primary issue in NSPI (National Society for Performance and Instruction) as well as ASTD (American Society for Training and Development), AECT (Association for Educational

Communications and Technology) and other professional societies. 
Consequently there has been much activity related to developing certification, credentialing, or licensing for practitioners in the field of human performance technology. (Gilley, et al, 1987, p.7)

No matter what your opinion about the issue of certification, it appears that a number of the organizations that claim to speak for the training and human performance improvement professions have embarked on a study, not only of whether to certify, but how to go about it. This is consistent with the continued evolution of the profession.

It is safe to say that we will only be hearing more about this issue in the future. Because the establishment of a certification program is likely to affect all the members of the profession, it behoves us to become informed about the pro's and con's of certification, as well as the standards that are very likely to serve, in some way, as measures of competence.

\section{ANSWERS - confronting the issues}

\section{Knowing when training is NOT appropriate}

The standards / competencies we have been discussing are all related to the training function. If the competencies are properly applied, however, training may not take place at all. Implicit in any performance improvement process - and included in the competencies ( Instructional Designer \#2, Training Manager \#1 ) - is a good needs assessment that determines whether there is a gap in the actual and desired performance or productivity of an organization, what causes the gap, and what can close it.

Training is only one of many solutions to performance or productivity problems and it is appropriate only when you want to influence / change the knowledge, skills or attitudes of the workers. And, in fact, other elements such as incentive programs, motivation programs and feedback programs can change the worker - sometime more effectively than training. When you are concerned with policy or environment - those elements that support the worker - you're looking at solutions in the workplace. And often the design, expectations, procedures, documentation or technology related to the performance of the job itself will have to be altered to eliminate the gap between the actual and ideal performance. (Rosenberg, 1990)

Almost without exception, training is the most expensive of the interventions mentioned above. As a result, the credibility of the training profession will be enhanced - not harmed - by those of us who can help organizations identify when training is not the proper solution to a performance or productivity problem. 
Preventing some of the problems that typically plague the growth and development of a profession

As a result of fluctuating business cycles, increased mobility and a greater desire for job satisfaction; it is predicted that the average worker of the 21st century will be making two to three job/career changes in his or her lifetime. (Train America's Workforce, p.44, 1990) This will only increase the demand for training, which will lead to a greater influx of people into the profession. This, in turn, means that the leadership of the profession will have to make room for others who want to share the power and contribute to the development of the field. In other professions, this dynamic has sometimes had a negative impact.

After initial periods of innovation and the product differentiation, there is a period of legitimation, accreditation and development of ethical codes. Then there is often a period of monopolization: control over entry, and other practices to eliminate competition. This then leads to a period of exploitation, subordinating clients' needs, and finally to a defensive period when clients begin to rebel. (Shepard, 1982, in Eisen, p.4, 1990)

By putting an emphasis on professional competencies and the development of exemplary performance standards, we can emphasize the responsibility of training managers to provide for the career development that will enable people to perform well, not exclude them because they can't.

\section{Enhancing professional credibility}

As mentioned above, one of the first things that begins to define a profession is the language - or jargon - with which its members describe what they do. This enables practitioners to communicate with each other about their roles and functions with some degree of common understanding. It does not, however, mean that they agree regarding roles or functions, and it often excludes those outside the profession who do not know the "language."

By identifying the minimum tasks that are necessary for training to bring about improvement in productivity or performance, and spelling out who does what by when; competencies reduce the variance with which roles and functions are viewed within the profession. They also make more precise the tasks we engage in and the processes by which these tasks are accomplished. This precision enables us to communicate more clearly what we are about and thereby increases the degree of professional unity we project. It also enables the lay person to better understand the roles, functions and processes involved in training and the theories that underlie them. Together these go a long way toward enhancing professional credibility. 


\section{References}

Deeprose, D. (1989). Rating performance appraisals: unsatisfactory, Training, August, 86.

Eisen,S., Stelle, H. and Cherbeneau J. (1990). Developing OD competencies for the 90 s and beyond: Conclusions from a delphi conference, $O D$ Practitioner, June 4, 4.

Erickson, P.R. (1990). Evaluating training results. Training and Development Journal, January, 57-59

Gilbert, T. (1978). Human Competence: Engineering Worthy Performance. New York, NY: McGraw Hill.

Gilbert, T. (1979). Human incompetence: the autobiography of an educational revolutionist, NSPI Journal, July, 19.

Gilley, J., Geis, G, \& Seyfer, C. (1987). Let's talk certification: Questions and answers for the profession about the profession. Performance and Instruction, February, 7-17.

Hultman, K. E. (1988). The psychology of performance management. Training and Development Journal, July, 34-39.

Instructional Design Competencies: The Standards. (1986). Iowa City, IA: International Board of Standards for Training, Performance and Instruction.

Instructor Competencies: The Standards. (1988). Evergreen, CO: International Board of Standards for Training, Performance and Instruction.

Mager, R. (1984). Preparing Instructional Objectives, Belmont, CA: Lake Publishing Company.

Nadler, L. (1984). Human resource development, In L. Nadler (Ed.) The Handbook of Human Resource Development. New York, NY: John Wiley \& Sons, 1.6-1.13.

Prahalad, C.K., and Hamel, G. (1990). The core competence of the corporation. Harvard Business Review, May-June, 79-91.

Professional Reference Guide to the Competencies - the Standards for Instructors, Instructional Designers, and Training Managers, (1989). Chicago, IL.: International Board of Standards for Training, Performance and Instruction.

Rosenberg, M.J. (1990). Performance technology: Working the system. Training, February, 42-48.

Rosenthal, R. and Jacobson, L.F. (1968). Teachers expectations for the disadvantaged. Scientific American, 4, 19-23.

Shepard, H. (1982). The irony of a mature helping profession. In S. Eisen, et al, Developing OD competencies for the 90s and beyond: Conclusions from a delphi conference, (1990) OD Practitioner, June, 4.

Smith, J.E. and Merchant, S. (1990). Using competency exams for evaluating training. Training, August, 65-71.

Train America's workforce, (1990). Training and Development Journal, June, 44. 
Training Manager Competencies: The Standards. (1989). Chicago, IL: International Board of Standards for Training, Performance and Instruction.

Author: Peter J. Dean, Assistant Professor of Education and Regional Coordinator: Instructional Systems Program, Penn State University, 30 East Swedesford Road, Malvern, PA19355. Telephone 215-889-1300.

Dr. Dean is Assistant Professor and Regional Coordinator of The Pennsylvania State University - Great Valley Center's Master's Degree Program in Training Design and Development Dr. Dean has 20 years experience in both business and academic arenas designing, implementing and evaluating training programs in areas of communication skills, leadership, problem solving, team building, interpersonal relations, decision making, stress management, train-the-trainer and organizational change. His audiences have included business and industry professionals, college and university administrators and faculty, and government and health care officials.

Currently Dr. Dean is Vice President of Research for the International Board of Standards for Training, Performance and Instruction. He also serves on the Ethics Committee for the Association for Educational Communication and Technology.

Please cite as: Dean, P. J. (1990). Using standards to improve performance. Australian Journal of Educational Technology, 6(2), 75-91. http: / / www.ascilite.org.au/ajet/ ajet6/dean.html 